\title{
Bone Mineral Density in Women Living with Complete Androgen Insensitivity Syndrome and Intact Testes or Removed Gonads
}

\author{
Silvano Bertelloni ${ }^{a}$ Maria C. Meriggiola ${ }^{b}$ Elenora Datid ${ }^{d}$ Antonio Balsamo $^{c}$ \\ Giampiero I. Baroncelli ${ }^{a}$ \\ a Pediatric Division, Department of Obstetrics, Gynecology and Pediatrics, Azienda Ospedaliero-Universitaria Pisana, \\ Pisa, ${ }^{b}$ Gynecology and Physiopathology of Reproduction and ' Pediatric Endocrine Unit, Department of Pediatrics, \\ S. Orsola-Malpighi Hospital, University of Bologna, Bologna, and d Division of Pediatrics, San Giuseppe Hospital, \\ ASL 11, Empoli, Italy
}

\section{Keywords}

Bone health . Complete androgen insensitivity syndrome . Gonadal removal · Sex steroid substitutive therapy - Testes

\begin{abstract}
Complete androgen insensitivity syndrome (CAIS) is due to complete androgen resistance in androgen-dependent tissues. Since androgens are involved in growth, development, and mass maintenance of the skeleton, bone health may be a relevant clinical issue for improving quality of life of women living with CAIS. Bone mineral density (BMD) in women with CAIS and intact gonads has been reported in a normal range, although exceptions are known showing a low BMD mainly at the lumbar level. In women with CAIS and removed gonads, BMD is usually reduced at both the lumbar spine and femoral neck. However, the fracture risk remains largely unknown. In women with CAIS, hormonal replacement therapy may improve BMD, but it does not normalize it. Several factors may be operative (e.g., loss of AR signaling at the bone level, gonadal removal, and age at surgery [before or after attainment of the peak bone mass], inadequate sex steroid replacement therapy, poor compliance with hormonal
\end{abstract}

\section{KARGER}

๑ 2017 S. Karger AG, Basel

E-Mail karger@karger.com

www.karger.com/sxd treatment, high serum FSH levels, lack of testicular protein hormones after gonadal removal), but they are poorly evaluated. In conclusion, the maintenance of testes may represent a strategy to improve bone health in women with CAIS, but a strict follow-up to monitor the cancer risk is mandatory mainly from their 20 s onwards. Optimal sex steroid substitutive therapy in adolescence and adulthood is a key factor to improve BMD status in women with CAIS and removed gonads, but conclusive data on optimal management are lacking.

(c) 2017 S. Karger AG, Basel

Sex steroids act on the growing skeleton, contribute to maintain skeletal homeostasis, and play a key role in some aspects of bone dimorphism between males and females from puberty onward [Parfit, 1994; Seeman, 2001; Baroncelli and Bertelloni, 2009]. Sex steroid effects on bone are mainly exerted by activations of specific peripheral receptors (i.e., androgen receptor $[\mathrm{AR}]$ and estrogen receptor- $\alpha$ [ER- $\alpha]$ ) in osteoblasts, osteoclasts, osteocytes, and growth plate chondrocytes as well as an age-related sex-specific hormonal milieu [Vanderschueren et al., 2004; Baroncelli
Silvano Bertelloni

Pediatric Division, Department of Obstetrics, Gynecology and Pediatrics Azienda Ospedaliero-Universitaria Pisana

Via Roma 67, IT-56126 Pisa (Italy)

E-Mail s.bertelloni@ao-pisa.toscana.it 
Table 1. BMD in late adolescents/young women with CAIS and intact gonads

\begin{tabular}{lllll}
\hline Reference & Age, years & AR gene analysis & \multicolumn{2}{l}{ BMD, SD } \\
\cline { 4 - 5 } & & & lumbar (L2-L4) & femoral neck \\
\hline Soule et al. [1995] & 29 & no & -1.5 & -1.2 \\
Muñoz-Torres et al. [1995] & 17 & no & -4.1 & - \\
Mizunuma et al. [1998] & 19 & no & -0.8 & 0.2 \\
Bertelloni et al. [1998] & 28 & no & -3.1 & -0.7 \\
Sobel et al. [2006] & 16 & yes & -1.5 & -1.3 \\
Danilovic et al. [2007] & 17 & $?$ & -3.9 & -0.1 \\
Chin et al. [2012] & 21 & $?$ & $-1.6^{\mathrm{a}}$ & -1.2 \\
\hline
\end{tabular}

BMD, Bone mineral density; SD, standard deviation. ${ }^{\text {a }}$ In respect to calculated apparent volumetric BMD.

and Bertelloni, 2009; Rochira and Carani, 2009; Callewaert et al., 2010; Laurent et al., 2014]. Therefore, the skeletal phenotype of the 2 sexes and bone health are influenced by an adequate sex steroid production and metabolism during life as well as an optimal response to their peripheral actions. Testosterone is the main androgen hormone secreted by the testes; it may also be considered as a pro-hormone, as it can be metabolized to $5 \alpha$-dihydrotestosterone by $5 \alpha$-reductase- 2 and to $17 \beta$-estradiol by P450 aromatase [Baroncelli and Bertelloni, 2009; Rochira and Carani, 2009]. Thus, testosterone may act via AR signaling or indirect by ER- $\alpha$ signaling. Different actions of estrogens and androgens on skeletal muscles and mechanostat sensitivity may also be involved in bone health and sexual dimorphism between males and females [Frost and Schönau, 2000].

Complete androgen insensitivity syndrome (CAIS) is caused by mutations in the $A R$ gene, determining loss of AR function and complete androgen resistance in androgen-dependent tissues; it affects 1 in 20,000-90,000 neonates [Hughes et al., 2012]. Women with CAIS present with a 46,XY karyotype, normal secreting testes, and normal external female genitalia and body habitus [Hughes et al., 2012]. In adult women with CAIS, reduced bone mineral density (BMD) has been reported [reviewed in Bertelloni et al., 2010]. The low BMD may be due to the impaired AR action, but the practice of removing gonads to prevent cancer risk may contribute to this finding [reviewed in Bertelloni et al., 2010]. Osteoporosis risk is a concern for women living with CAIS (www.aissg.org; www.aisia.org; www.grapsia.org), and optimal strategies to improve bone health should be developed.

Bone Health in CAIS
This paper reviews the bone status of adult women living with CAIS who maintained their gonads or had their gonads removed.

\section{BMD Status in Women Living with CAIS and Intact Gonads}

Very few data are available on BMD in females with CAIS and intact gonads (Table 1). Variable results have been reported, but a tendency to reduced BMD values has been found, mainly at the lumbar spine. Lumbar BMD scans below -2.5 standard deviations (SD) (that is the cutoff to define osteoporosis according to WHO) [NIH Consensus, 2001] were reported in 5/10 women [Muñoz-Torres et al., 1995; Soule et al., 1995; Bertelloni et al., 1998; Mizunuma et al., 1998; Tian et al., 2005; Danilovic et al., 2007; Chin et al., 2012] (Table 1). All femoral neck measurements were within the normal range, even though below the 0 SD in 6/9 persons [Soule et al., 1995; MuñozTorres et al., 1995; Mizunuma et al., 1998; Bertelloni et al., 1998; Tian et al., 2005; Danilovic et al., 2007; Chin et al., 2012] (Table 1).

The discrepancy among the various reports (Table 1) is unclear, but issues such as reference values for DXA (dual-energy X-ray absorptiometry) scans, auxological parameters, vitamin D status, diet, and life styles may be involved, but they were poorly explored. In addition, molecular analysis of the $A R$ gene was not always performed.

Recently, we examined 10 adult women with proven CAIS and intact gonads [Meriggiola et al., 2015]. Lumbar

Sex Dev 2017;11:182-189 183 
Fig. 1. Lumbar and femoral neck BMD in adult women living with CAIS and intact (open columns) and removed (black columns) gonads (data summarized from Meriggiola et al. [2015]). ${ }^{*} p<0.001$ vs. intact gonads.

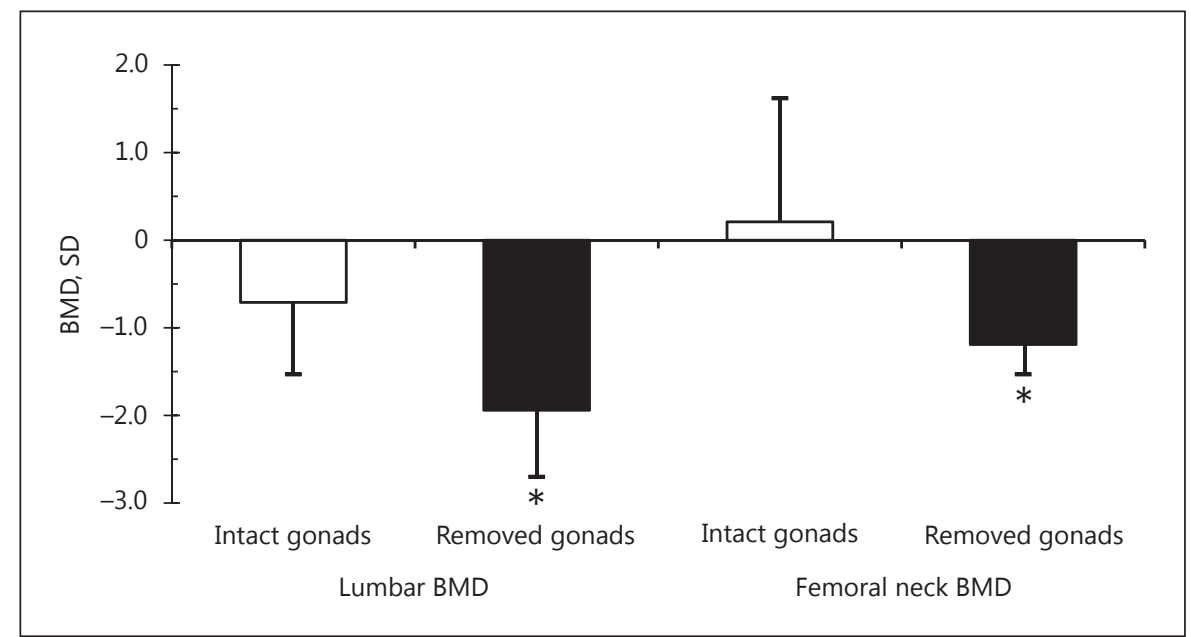

Table 2. Bone mineral status in late adolescent/adult women living with CAIS and removed gonads: cross-sectional data

\begin{tabular}{|c|c|c|c|c|c|c|c|c|}
\hline \multirow[t]{2}{*}{ Reference } & \multirow[t]{2}{*}{$n$} & \multirow{2}{*}{$\begin{array}{l}\text { AR gene } \\
\text { analysis }\end{array}$} & \multicolumn{2}{|c|}{ Mean age $\pm S D$, years } & \multicolumn{2}{|l|}{ ERT } & \multicolumn{2}{|c|}{$\mathrm{BMD}, \mathrm{SD}$ or $\%$} \\
\hline & & & at DXA & at $\mathrm{Gnx}$ & E2 daily & compliance & lumbar & femoral neck \\
\hline Soule et al. [1995] & 4 & no & $32.7 \pm 10.4$ & $15.8 \pm 12.9$ & variable & variable & $-2.6 \pm 0.9$ & $-1.8 \pm 0.8$ \\
\hline Vered et al. [1997] & 1 & no & 39 & 32 & no & - & $-19 \%$ & $-22 \%$ \\
\hline Bertelloni et al. [1998] & 7 & yes & $17.7 \pm 2.2$ & $15.4 \pm 1.8$ & $\mathrm{TE} 50 \mathrm{mg}$ & variable & $-3.0 \pm 1.2$ & - \\
\hline Marcus et al. [2000] & 18 & no & $41.7 \pm 9.1$ & $13.3 \pm 5.0$ & CE $0.625-2.5 \mathrm{mg}$ & variable & $-1.2 \pm 1.1$ & $-0.8 \pm 1.1$ \\
\hline Tian et al. [2005] & 7 & $?$ & $?$ & $?$ & CE $0.3-0.625 \mathrm{mg}$ & $?$ & $-2.0 \pm 0.4$ & $-0.3 \pm 0.7$ \\
\hline Sobel et al. [2006] & 12 & partial & $35.2 \pm 14.3$ & $23.4 \pm 8.6$ & variable & variable & $-2.4 \pm 1.0$ & $-0.65 \pm 1.0$ \\
\hline Danilovic et al. [2007] & 5 & yes & $23.0 \pm 2.1$ & $19.1 \pm 5.3$ & CE $0.625 \mathrm{mg}$ & good/fair & $-1.4 \pm 1.1$ & $0.1 \pm 0.8$ \\
\hline Han et al. [2008] & 46 & partial & $32.2 \pm 10.7$ & $15.9 \pm 7.3$ & variable & good & $-1.3 \pm 1.2$ & $-0.6 \pm 1.0$ \\
\hline Taes et al. [2009] & 1 & yes & 31 & 15 & $\begin{array}{l}\text { no (from } 17 \text { to } 34 \\
\text { years) }\end{array}$ & & -3.4 & -1.7 \\
\hline
\end{tabular}

BMD, Bone mineral density; CE, orally conjugated estrogens; DXA, dual-energy X-ray absorptiometry; ERT, estrogen replacement therapy; Gnx, gonadectomy; SD, standard deviation; TE, transdermal $17 \beta$-estradiol.

BMD values were below the mean, although not significantly reduced, while femoral BMD was slightly above the mean (Fig. 1, open columns). No woman showed lumbar or femoral BMD below -2.5 SD. Lumbar BMD was significantly reduced in comparison with femoral neck BMD (Fig. 1, open columns).

These results suggest that bone health seems not to be grossly impaired in the majority of adults with CAIS who maintained their gonads. Indeed, lumbar BMD is more affected than femoral BMD. Thus, a particular sensibility of trabecular bone to AR signaling impairment seems to be operative [Sobel et al., 2007; Danilovic et al., 2007; Bertelloni et al., 2010]. In this regard, experimental studies showed that osteoblasts and osteocytes are the target cells for AR-mediated maintenance of trabecular bone as well as the main players of coupling between bone matrix synthesis and mineralization [Vanderschueren et al., 2004; Callewaert et al., 2010; Sinnesael et al., 2012].

\section{BMD Status in Women Living with CAIS and Removed Gonads}

Reduced BMD has been clearly reported in adolescents and women with CAIS and removed gonads with some differences among the various studies (Table 2) [Soule et al., 1995; Vered et al., 1997; Bertelloni et al., 1998; Marcus et al., 2000; Tian et al., 2005; Sobel et al., 
2006; Danilovic et al., 2007; Han et al., 2008; Taes et al., 2009]. Also in this group, lumbar BMD was usually more affected than femoral neck BMD (Table 2). Some studies included single individuals [Vered et al., 1997; Taes et al., 2009] or small samples [Soule et al., 1995; Bertelloni et al., 1998; Sobel et al., 2006; Danilovic et al., 2007], but such findings have been confirmed in relative large series for this rare condition [Marcus et al., 2000; Han et al., 2008].

BMD scans were carried out in heterogeneous populations regarding age at gonadectomy, hormonal replacement therapy (HRT; formulations and doses), and certainty of diagnosis at the molecular level (Table 2). In one study, the diagnosis was self-reported by participants [Marcus et al., 2000]. Therefore, subjects affected by other 46,XY disorders of sex development might have been enrolled in some studies. In addition, normative data to evaluate BMD did not always match with the ethnic origin of the investigated people [Sobel et al., 2006; Danilovic et al., 2007].

We measured BMD in a series of 43 women with proven CAIS and removed gonads, showing significantly reduced lumbar and femoral neck BMD (Fig. 1, black columns) [Meriggiola et al., 2015]. Lumbar BMD was significantly below femoral neck BMD (Fig. 1, black columns). In addition, both lumbar and femoral neck BMD were significantly reduced in comparison with those measured in the group of women with intact gonads (Fig. 1) [Meriggiola et al., 2015]. Albeit variable age at gonadectomy and HRT protocols were present also in our series, homogeneous DXA scans were obtained and results were compared with appropriate reference populations.

\section{Fracture Rate in Women Living with CAIS}

Low BMD is a major risk factor for fractures [NIH Consensus, 2001]. No data on the fracture rate are available in the literature for women with CAIS and intact testes, but we did not find any fractures in the 10 females we studied [Meriggiola et al., 2015]. A high fracture rate has been reported in the study of Marcus et al. [2000] in women with removed gonads $(6 / 22 ; 27.3 \%)$. Multiple fractures also occurred in 1 out of 6 women in the study of Soule et al. [1995] and in that described by Taes et al. [2009]. In our previous series of 10 girls and adolescents, no fractures were recorded [Bertelloni et al., 1998], while 1/43 women $(2.3 \%)$ of our recent adult sample reported a fracture [Meriggiola et al., 2015]. In other studies, the fracture

Bone Health in CAIS rate was not explored. Albeit such fractures may be related to a low BMD, available data do not permit definite conclusions due to the limited number of persons enclosed in each study.

\section{Causes of Impaired BMD in Women Living with CAIS}

In CAIS, absent AR action at the bone tissue level may contribute per se to the low BMD values; trabecular bone seems to be mainly affected as suggested by the lower lumbar BMD in comparison with femoral neck BMD (Fig. 1; Table 1).

Impaired BMD has been related to gonadectomy followed by inappropriate HRT, poor compliance with treatment, or inadequate doses of sex steroids, typically estrogens [Soule et al., 1995; Marcus et al., 2000; Sobel et al., 2006; Danilovic et al., 2007; Han et al., 2008; Taes et al., 2009]. In fact, adults with CAIS and good HRT showed better lumbar and femoral BMD values [Han et al., 2008; Marcus et al., 2000; Meriggiola et al., 2015]. Indeed, the majority of women with CAIS and removed gonads showed only mild or no improvement of their BMD during estrogen administration mainly at the lumbar level (Fig. 2). No improvement of apparent volumetric lumbar BMD has been also observed during 2 years of $0.625 \mathrm{mg}$ conjugated estrogens [Danolovic et al., 2007]. Thus, usual HRT schemes may be not optimal for bone health (doses, route of administration) or other factors may be involved.

With regard to HRT, a relevant increase of lumbar BMD during high-normal estrogen therapy has been reported in a single person, but it remained at -2.0 SDS at the end of a 5-year follow-up period (Fig. 2) [Taes et al., 2009]. In this woman, peripheral quantitative computed tomography documented estrogen-specific effects on bone envelopes, showing a gradual increase in trabecular and cortical bone density $(+6.5 \%$ and $+2.1 \%$, respectively) and in cortical thickness $(+3 \%)$ as the result of endosteal contraction $(-1.0 \%)$ without marked influence on periosteal bone apposition [Taes et al., 2009]. Therefore, young women with CAIS may require higher doses of substitutive therapy, while the majority would receive low-normal standard doses (i.e., equivalent to $0.625-1.25$ $\mathrm{mg}$ of conjugated estrogens) [Birnbaum and Bertelloni, 2014]. It must be considered that the recommended premenopausal adult daily dose may reach $100-200 \mu \mathrm{g}$ of transdermal $17 \beta$-estradiol (equivalent to $2-4 \mathrm{mg}$ of oral micronized $17 \beta$-estradiol or $1.25-2.5 \mathrm{mg}$ of conjugated estrogens) [Bondy et al., 2007]. The route of administration and formulations may also affect the BMD status. For

Sex Dev 2017;11:182-189 DOI: $10.1159 / 000477599$ 


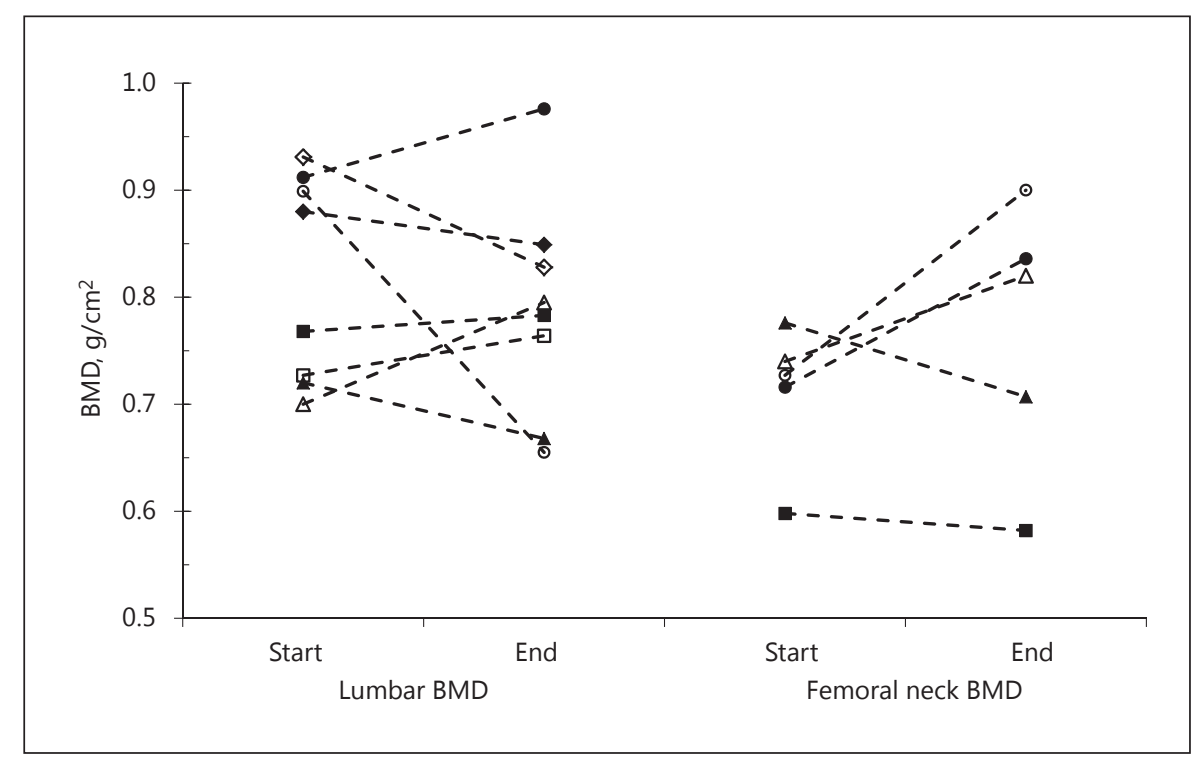

Fig. 2. Individual variations of lumbar and femoral neck BMD in adult women living with CAIS during hormonal replacement therapy. Suole et al. [1995], patient \#3, gonadectomy at 29 years (Start) CEE $0.625 \mathrm{mg} /$ day for 2 years (End). - Suole et al. [1995], patient \#4, gonadectomy at 24 years; treatment CEE $0.625 \mathrm{mg}$ /day from 24 to 38 years (Start) CEE $0.625 \mathrm{mg} / 5$ days out of $7+$ cyclic etidronate for 18 months (End). $\boldsymbol{\Delta}$ Muñoz-Torres et al. [1995], gonadectomy at 17 years (Start) E valeraniate $(2.0 \mathrm{mg} /$ day $)+$ norgestrel $(0.5 \mathrm{mg})$ for 4 years (End). Vered et al. [1997], gonadectomy at 32 years; at 39 years, CEE $1.25 \mathrm{mg} /$ day (Start) for 4 years (End). $\diamond$ Mizunuma et al. [1998], patient \#1, gonadectomy at 19

example, in adolescents with Turner syndrome, transdermal estrogens determined a greater increase in BMD in respect to oral conjugated estrogens [Nabhan et al., 2009].

With regard to other factors, the elevated FSH levels in women with removed gonads, which are related to the lack of inhibins produced by the Sertoli cells [Melo et al., 2003; Audi et al., 2010], may play a role. Experimental studies indicated that osteoclastic bone resorption may be triggered in hypogonadal rodents via activation of the FSH receptor and TNFa production by bone marrow [Iqbal et al., 2006; Sun et al., 2006]. A specific FSH antibody is able to block the FSH effect on osteoclast formation in vitro and, when injected into ovariectomized mice, attenuates bone loss [Zhu et al., 2012]. Indeed, FSH serum levels in women with CAIS and intact gonads did not differ from normal adult values or were slightly elevated in a minority of subjects [Melo et al., 2003; Doehnert et al., 2015].

Finally, testicular hormones other than sex steroids may be involved in the differences between women with years; at 19.5 years, CEE $1.25 \mathrm{mg} /$ day $+10 \mathrm{mg}$ MPA (Start) for 1 year (End). $\square$ Mizunuma et al. [1998], patient \#2, gonadectomy at 28 years; at 28.3 years, CEE $1.25 \mathrm{mg} /$ day $+10 \mathrm{mg}$ MPA (Start) for 3 years (End). $\triangle$ Taes et al. [2009], gonadectomy at 15 years; E valeraniate $2.0 \mathrm{mg} /$ day from 15 to 17 years; then no treatment until 31 years (Start): transdermal estradiol for 5 years (End) (doses $0.3 \mathrm{mg}$ /day until $3.0 \mathrm{mg} /$ day from the end of first year of followup). O Personal observation, gonadectomy at 23 years; estrogen treatment (various regimens, poor compliance) until 40 years (Start): intramuscular testosterone undecanoate $(1,000 \mathrm{mg} / 90$ days) for 3 years (End). intact or removed gonads. For example, INSL3, the testisspecific protein hormone secreted by Leydig cells, may act on bone by inducing the expression of some key osteoblast genes for osteoblast differentiation, matrix deposition, and osteoclastogenesis. It may also act by stimulation of mineralization and/or promoting better function of the muscle-skeletal unit [Ferlin et al., 2016]. Even though the INSL3 status of women with CAIS who maintained their gonads is unknown, this hormone is obviously absent in those females who underwent gonadal removal. Surgery before or after the attainment of the peak bone mass may be an additional factor.

\section{How to Optimize Bone Health in CAIS}

Tentative indications to optimize bone health in CAIS are summarized in Table 3.

The maintenance of gonads may represent a strategy, but a strict follow-up must be warranted [Deans et al., 
Table 3. Bone health in CAIS: indications for practice and research

\begin{tabular}{|c|c|c|c|}
\hline \multicolumn{2}{|l|}{ BMD status } & \multicolumn{2}{|l|}{ Actions to improve BMD } \\
\hline clinical evidence & research agenda & actually available & research agenda \\
\hline $\begin{array}{l}\text { Reduced BMD, mainly } \\
\text { at lumbar spine, in } \\
\text { women with removed } \\
\text { gonads }\end{array}$ & $\begin{array}{l}\text { To be evaluated: } \\
\text { - Longitudinal assessment of BMD } \\
\text { before and after gonadectomy } \\
\text { - Bone geometry, strength, and } \\
\text { shape } \\
\text { - Muscle-skeletal unit inferences } \\
\text { - Bone accrual from infancy to } \\
\text { adolescence }\end{array}$ & $\begin{array}{l}\text { - Maintain gonads as long as possible } \\
\text { - Optimize estrogen therapy from puberty } \\
\text { onward in women with removed gonads: } \\
\text { use } 17 \beta \text {-estradiol (transdermal) } \\
\text { formulations and doses adequate for } \\
\text { young adults with impaired AR action } \\
\text { - Avoid administration of progestins } \\
\text { (mainly medroxyprogesterone acetate) } \\
\text { - Optimize intake of calcium, vitamin D, } \\
\text { and fitness }\end{array}$ & $\begin{array}{l}\text { - Supplemental estrogens } \\
\text { in women with intact } \\
\text { gonads and low BMD } \\
\text { - Testosterone therapy } \\
\text { (instead of estrogens) in } \\
\text { women with proven CAIS } \\
\text { diagnosis }^{\text {d }} \\
\text { - Adjunctive INSL3 } \\
\text { administration in women } \\
\text { with removed gonads }^{\mathrm{d}}\end{array}$ \\
\hline \multicolumn{4}{|c|}{$\begin{array}{l}\text { BMD, bone mineral density. } \\
\text { a Gonads must be strictly followed up (by ultrasound, at least yearly). } \\
\text { b There is no evidence that cyclic progesterone is beneficial in women without a uterus, but some data suggest that medoxyprogesterone } \\
\text { etate may have negative effects on bone. } \\
{ }^{c} \text { To be explored; safety of high estrogen doses (if used) in CAIS should be proven and accurately monitored. } \\
\text { d To be explored. }\end{array}$} \\
\hline
\end{tabular}

2012; Wünsch et al., 2012]. These women must be fully and clearly informed about the cancer risk, and an annual follow-up of testes by ultrasound should be carried out at least from the age of 20 onward [Deans et al., 2012].

Since some women with intact gonads anyway may show reduced BMD values (Table 1), it has been suggested that this subset could benefit from treatment with additional estrogens even in the presence of intact testes [Warne et al., 2005]. Clinical data addressing this hypothesis are not available, and the safety of this procedure has not been explored.

When gonads have been removed, doses and formulations of sex steroid substitutive therapy must be optimized for women living with CAIS, recommending the use of transdermal estrogen deliveries and strictly monitoring compliance. Progestins should be avoided in these women without uterus, mainly medroxy-progesterone acetate, for its possible direct or indirect negative effects on bone [Committee Opinion, 2014].

In women with proven CAIS, testosterone is the main sex steroid hormone secreted by their gonads [Melo et al., 2003; Doehnert et al., 2015]. Thus, this hormone might be used for substitutive therapy instead of estrogens (German Clinical trials register: trials DRKS-ID DRKS00003136; https://drks-neu.uniklinik-freiburg.de), titrating the doses upon the sex steroid values reported in women with intact gonads [Doehnert et al., 2015] to take advantage of the nongenomic action of this hormone on skeletal muscle and osteoblasts [Lieberherr and Grosse, 1994; Dent et al., 2012]. At present, data supporting this approach to improve bone health are lacking. In a woman treated with testosterone undecanoate (1,000 mg i.m./90 days), we found an increase of lumbar BMD (Fig. 2), but femoral neck BMD decreased from 0.931 to $0.732 \mathrm{~g} / \mathrm{cm}^{2}$. So, more data are needed to draw some conclusions.

It should also be considered that women with CAIS may have a specific bone phenotype. Thus, female or male reference values could be inadequate to evaluate DXA scans in these persons, and only the assessment of the fracture rate in large samples will permit a true estimation of bone risk. In addition, bone geometry, strength, and shape and their inferences on bone health are poorly explored. Thus, specific longitudinal studies are needed to highlight these issues.

Finally, bone growth and maturation and bone mass accrual during prepubertal years and during mid to late adolescence, when large part of the bone mass is gained, should be better evaluated in order to obtain more information on pre- and postnatal inferences of androgens on the development of the bone phenotype, which will influence bone health during life. Furthermore, general factors (i.e., vitamin D status, calcium assumption, fitness, body weight, smoking, drinking, etc.) should be optimized in order to improve bone health in women living with CAIS as in the general population. 


\section{Acknowledgement}

The authors wish to thank the Italian Androgen Insensitivity Syndrome Support Group (AISIA). This paper was developed under the auspices of the Italian Society for Pediatric Research.

\section{Disclosure Statement}

The authors have no conflicts of interest to declare.

\section{References}

Audi L, Fernández-Cancio M, Carrascosa A, Andaluz P, Torán N, et al: Novel (60\%) and recurrent (40\%) androgen receptor gene mutations in a series of 59 patients with a $46, \mathrm{XY}$ disorder of sex development. J Clin Endocrinol Metab 95:1876-1888 (2010).

Baroncelli GI, Bertelloni S: The effects of sex steroids on bone growth, in Orwoll E, Bilezikian J, Vanderschueren D (eds): Osteoporosis in Men, ed 2, pp 105-118 (Elsevier Inc., New York 2009).

Bertelloni S, Baroncelli GI, Federico G, Cappa M, Lala R, Saggese G: Altered bone mineral density in patients with complete androgen insensitivity syndrome. Horm Res 50:309-314 (1998).

Bertelloni S, Baroncelli GI, Mora S: Bone health in disorders of sex differentiation. Sex Dev 4: 270-284 (2010).

Birnbaum W, Bertelloni S: Sex hormone replacement in disorders of sex development. Endocr Dev 27:149-159 (2014).

Bondy CA, Turner Syndrome Study Group: Care of girls and women with Turner syndrome: a guideline of the Turner Syndrome Study Group. J Clin Endocrinol Metab 92:10-25 (2007).

Callewaert F, Boonen S, Vanderschueren D: Sex steroids and the male skeleton: a tale of two hormones. Trends Endocrinol Metab 21:8995 (2010).

Chin VL, Sheffer-Babila S, Lee TA, Tanaka K, Zhou P: A case of complete androgen insensitivity syndrome with a novel androgen receptor mutation. J Pediatr Endocrinol Metab 25:1145-1151 (2012).

Committee Opinion No. 602: Depot medroxyprogesterone acetate and bone effects. Obstet Gynecol 123:1398-1402 (2014).

Danilovic DL, Correa PH, Costa EM, Melo KF, Mendonca BB, Arnhold IJ: Height and bone mineral density in androgen insensitivity syndrome with mutations in the androgen receptor gene. Osteoporos Int 18:369-374 (2007).

Deans R, Creighton SM, Liao LM, Conway GS: Timing of gonadectomy in adult women with complete androgen insensitivity syndrome (CAIS): patient preferences and clinical evidence. Clin Endocrinol (Oxf) 76:894-898 (2012).
Dent JR, Fletcher DK, McGuigan MR: Evidence for a non-genomic action of testosterone in skeletal muscle which may improve athletic performance: implications for the female athlete. J Sports Science Med 11:363-370 (2012).

Doehnert U, Bertelloni S, Werner R, Dati E, Hiort $\mathrm{O}$ : Characteristic features of reproductive hormone profiles in late adolescent and adult females with complete androgen insensitivity syndrome. Sex Dev 9:69-74 (2015).

Ferlin A, De Toni L, Sandri M, Foresta C: Relaxin and INSL3 in the muscolo-skeletal system: from bench to bedside. Br J Pharmacol 174: 1015-1024 (2016).

Frost HM, Schönau E: The 'muscle-bone unit' in children and adolescents: a 2000 overview. J Pediatr Endocrinol Metab 13:571-590 (2000).

Han TS, Goswami D, Trikudanathan S, Creighton SM, Conway GS: Comparison of bone mineral density and body proportions between women with complete androgen insensitivity syndrome and women with gonadal dysgenesis. Eur J Endocrinol 159:179-185 (2008).

Hughes IA, Davies JD, Bunch TI, Pasterski V, Mastroyannopoulou K, MacDougall J: Androgen insensitivity syndrome. Lancet 380:14191428 (2012).

Iqbal J, Li S, Kumar TR, Blair HC, Zaidi M: Follicle-stimulating hormone stimulates TNF production from immune cells to enhance osteoblast and osteoclast formation. Proc Nat Acad Sci USA 103:14925-14930 (2006).

Laurent M, Antonio L, Sinnesael M, Dubois V, Gielen E, et al: Androgens and estrogens in skeletal sexual dimorphism. Asian J Androl 16:213-222 (2014).

Lieberherr M, Grosse B: Androgens increase intracellular calcium concentration and inositol 1,4,5-trisphosphate and diacylglycerol formation via a pertussis toxin-sensitive G-protein. J Biol Chem 269:7217-7223 (1994).

Marcus R, Leary D, Schneider Dl, Shane E, Favus M, Quigley CA: The contribution of testosterone to skeletal development and maintenance: lessons from the androgen insensitivity syndrome. J Clin Endocrinol Metab 85: 1032-1037 (2000).

Melo KF, Mendonca BB, Billerbeck AE, Costa EM, Inacio M, et al: Clinical, hormonal, behavioral, and genetic characteristics of androgen insensitivity syndrome in a Brazilian cohort: five novel mutations in the androgen receptor gene. J Clin Endocrinol Metab 88: 3241-3250 (2003).
Meriggiola MC, Dati E, Berra M, Bombardini C, Baldinotti F, et al: Bone mineral density in women with complete androgen insensitivity syndrome: effects of gonadal removal and sex steroids substitutive therapy. Oral Communication, 5th I-DSD Symposium. 11th-13th June, Ghent, Belgium; Abstracts Book (2015).

Mizunuma H, Soda M, Okano H, Kagami I, Miyamoto $\mathrm{S}$, et al: Changes in bone mineral density after orchidectomy and hormone replacement therapy in individuals with androgen insensitivity syndrome. Human Reprod 13: 2816-2818 (1998).

Muñoz-Torres M, Jodar E, Quesada M, EscobarJimenez F: Bone mass in androgen-insensitivity syndrome: response to hormonal replacement therapy. Calcif Tissue Inter 57:94-96 (1995).

Nabhan ZM, Dimeglio LA, Qi R, Perkins SM, Eugster EA: Conjugated oral versus transdermal estrogen replacement in girls with Turner syndrome: a pilot comparative study. J Clin Endocrinol Metab 94:2009-2014 (2009).

NIH Consensus Development Panel on Osteoporosis Prevention, Diagnosis, and Therapy: Osteoporosis prevention, diagnosis, and therapy. JAMA 285:785-795 (2001).

Parfitt AM: The two faces of growth: benefits and risks to bone integrity. Osteoporosis Inter 4: 382-398 (1994).

Rochira V, Carani C: Aromatase deficiency in men: a clinical perspective. Nature Rev Endocrinol 5:559-568 (2009).

Seeman E: Clinical review 137: sexual dimorphism in skeletal size, density, and strength. J Clin Endocrinol Metab 86:4576-4584 (2001).

Sinnesael M, Claessens F, Laurent M, Dubois V, Boonen S, et al: Androgen receptor (AR) in osteocytes is important for the maintenance of male skeletal integrity: evidence from targeted AR disruption in mouse osteocytes. J Bone Miner Res 27:2535-2543 (2012).

Sobel V, Schwartz B, Zhu YS, Cordero JJ, Imperato-McGinley J: Bone mineral density in the complete androgen insensitivity and 5a-reductase-2 deficiency syndromes. J Clin Endocrinol Metab 91:3017-3023 (2006).

Soule SG, Conway G, Prelevic GM, Prentice M, Ginsburg J, Jacobs HS: Osteopenia as a feature of the androgen insensitivity syndrome. Clin Endocrinol (Oxf) 43:671-675 (1995).

Sun L, Peng Y, Sharrow AC, Iqbal J, Zhang Z, et al: FSH directly regulates bone mass. Cell 125: 247-260 (2006). 
Taes Y, Lapauw B, Vandewalle S, Zmierczak H, Goemaere $S$, et al: Estrogen-specific action on bone geometry and volumetric bone density: longitudinal observations in an adult with complete androgen insensitivity. Bone 45: 392-397 (2009).

Tian QJ, Dai ZQ, Yu W, Tian JP, Lang JH: Study of bone mineral density incomplete androgen insensitivity syndrome patients (in Chinese). Zhonghua Fu Chan Ke Za Zhi 40:799-802 (2005).

\section{Note Added in Proof}

Recently, King et al. [2017] published a retrospective analysis of pre- and post-gonadectomy $\mathrm{BMD}$ parameters in a large sample of women with CAIS $(n=113$; age at gonadectomy $13.0-16.5$ years; age at latest DXA scan 31.4-36.3 years). T-score $\mathrm{BMD}$ at lumbar spine was $-1.34(-1.55$ to $-1.13 ; p<0.001)$ and at the hip $-0.3(-0.49$ to $-0.12 ; p=0.001)$. In this series, there was no relationship between age of gonadectomy and BMD. Thirty-two subjects had BMD measured before or within 2 years of gonadectomy, and mean BMD was re-
Vanderschueren D, Vandenput L, Boonen S, Lindberg MK, Bouillon R, Ohlsson C: Androgens and bone. Endocr Rev 25:389-425 (2004).

Vered I, Kaiserman I, Sela BA, Sack J: Cross genotype sex hormone treatment in two cases of hypogonadal osteoporosis. J Clin Endocrinol Metab 82:576-578 (1997).

Warne GL, Grover S, Zajac JD: Hormonal therapies for individuals with intersex conditions: protocol for use. Treat Endocrinol 4:19-29 (2005).

duced $(95 \% \mathrm{CI})$ at the lumbar spine (Tscore: -1.05 [ -1.54 to -0.57$] ; p<0.001)$ but was normal at the hip (T-score: -0.04 [ -0.35 to 0.28$] ; p=0.8)$. In addition, these authors did not report any drop in BMD in women with DXA scans both before and after gonadectomy $(n=12 ; 1.7-12.8$ years of follow-up). Taken together, the data confirm that lumbar spine BMD is more affected than that of the hip in women living with CAIS and that bone health represents a specific need of care, allowing recommending regular BMD monitoring in
Wünsch L, Holterhus PM, Wessel L, Hiort O: Patients with disorders of sex development (DSD) at risk of gonadal tumour development: management based on laparoscopic biopsy and molecular diagnosis. BJU Intern 110:E958-E965 (2012).

Zhu LL, Blair H, Cao J, Yuen T, Latif R, et al: Blocking antibody to the $\beta$-subunit of FSH prevents bone loss by inhibiting bone resorption and stimulating bone synthesis. Proc Nat Acad Sci USA 109:14574-14579 (2012).

all these subjects [King et al., 2017]. Indeed, the issue of true factors involved in low BMD in CAIS remains open for discussion and for further studies.

Reference

King TF, Wat WZ, Creighton SM, Conway GS Bone mineral density in complete androgen insensitivity syndrome and the timing of gonadectomy. Clin Endocrinol (Oxf), doi: 10.1111/cen.13368 (2017). 